$\begin{array}{ll} & \text { Etnográfica } \\ \text { etnográfica } & \text { Revista do Centro em Rede de Investigação em }\end{array}$

Antropologia

vol. 20 (1) | 2016

Vol. 20 (1)

\title{
Entidades espirituais: materializações, histórias e os índices de suas presenças
}

Spiritual entities: materializations, histories, and the index of their presences

\section{Marcelo Moura Mello}

\section{(2) OpenEdition}

Journals

\section{Edição electrónica}

URL: https://journals.openedition.org/etnografica/4193

DOI: 10.4000/etnografica.4193

ISSN: 2182-2891

\section{Editora}

Centro em Rede de Investigação em Antropologia

\section{Edição impressa}

Data de publição: 1 fevereiro 2016

Paginação: 211-225

ISSN: 0873-6561

\section{Refêrencia eletrónica}

Marcelo Moura Mello, «Entidades espirituais: materializações, histórias e os índices de suas

presenças», Etnográfica [Online], vol. 20 (1) | 2016, posto online no dia 03 março 2016, consultado o 09 fevereiro 2022. URL: http://journals.openedition.org/etnografica/4193 ; DOI: https://doi.org/10.4000/ etnografica. 4193

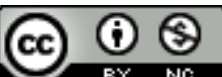

Etnográfica is licensed under a Creative Commons Attribution-NonCommercial 4.0 International License. 


\section{Entidades espirituais: materializações, histórias e os índices de suas presenças}

\section{Marcelo Moura Mello}

O ensaio sugere apropriações possíveis de duas coletâneas recentes - The Social Life of Spirits (2014) e Spirited Things: The Work of "Possession" in Black Atlantic Religions (2014) -, destacando os debates centrais em torno - e por meio - dos quais os efeitos, a agência e as presenças de entidades espirituais são pensados nos capítulos que compõem as obras. Na discussão de entidades espirituais, três temas são destacados: a materialidade, a história, e a operação de regimes semióticos por meio dos quais índices de presenças espirituais são pensados, conceituados e definidos pelos humanos.

PALAVRAS-CHAVE: espíritos, materialidade, história, possessão.

Spiritual entities: materializations, histories, and the index of their presences - The review suggests some appropriations of two recently edited volumes - The Social Life of Spirits (2014) e Spirited Things: The Work of "Possession" in Black Atlantic Religions (2014) - focusing on the central debates around and through which the effects, the agency and the presence of spiritual entities are thought in the chapters of both books. In the discussion of spiritual entities, three subjects are highlighted: materiality, history, and the operation of semiotics regimes through which indexes of spiritual presences are thought, conceptualized and defined by humans.

KEYWORDS: spirits, materiality, history, possession.

MELLO, Marcelo Moura (mmmello@gmail.com) - Departamento de Antropologia e Etnologia, UFBA, Brasil. 
BLANES, Ruy, e Diana ESPÍRITO SANTO (orgs.), 2014, The Social Life of Spirits. Chicago, The University of Chicago Press, 305 pp.

JOHnSON, Paul (org.), 2014, Spirited Things: The Work of "Possession" in Black Atlantic Religions. Chicago, The University of Chicago Press, 334 pp.

ESTE ENSAIO DELINEIA APROPRIAÇÕES POSSÍVEIS DE DUAS COLETÂNEAS recentes, The Social Life of Spirits (doravante, SLS), organizado por Ruy Blanes e Diana Espírito Santo (2014), e Spirited Things: The Work of Possession in Black Atlantic Religions (doravante, ST), volume compilado pelo antropólogo e historiador Paul Christopher Johnson (2014). ${ }^{1}$ As dificuldades de se escrever um artigo bibliográfico sobre coletâneas são bem conhecidas: variabilidade nas orientações teórico-metodológicas, oscilações qualitativas entre os capítulos, vocabulário técnico heteróclito, objetivos distintos e eventuais descompassos entre aquilo que é proposto pelos organizadores das coletâneas e o que é levado a cabo por colaboradores. Embora existam pontos de convergência evidentes entre as obras, como a atenção conferida à possessão espiritual, opta-se por destacar, inicialmente, duas temáticas mais amplas: a da materialidade e a da história. Ver-se-á que uma questão transversal a vários capítulos é a exploração etnográfica de regimes semióticos por meio dos quais presenças espirituais são pensadas, conceituadas e debatidas nos encontros de humanos com entidades espirituais. Essa ênfase visa, sobretudo, superar antinomias consolidadas no pensamento antropológico e romper com análises que concebem espíritos, meramente, como representações, esquemas mentais ou símbolos.

\section{MATERIALIDADE E HISTÓRIA: ÍNDICES DA PRESENÇA ESPIRITUAL}

É sabido que mortos, espíritos e ancestrais ocuparam um lugar de destaque na produção antropológica já nos primórdios da disciplina, desde as teorizações de Tylor (1871) até monografias pioneiras, como a de Malinowski (1988 [1916]). Não obstante, as tentativas de pensar os efeitos e as ações de entidades espirituais, bem como seu íntimo entrelaçamento com a vida de humanos em diversos espaços de experiência, foram, não raro, formuladas em domínios especializados. Na esteira de estudos recentes da antropologia da religião que colocam em questão a própria rentabilidade da categoria religião, pela apropriação criativa de vocabulário técnico heteróclito e por meio da inserção dos problemas relativos a, e colados por, entidades espirituais no centro de grandes

l Expresso meus agradecimentos às contribuições e ao interesse demonstrado por Rogério Wanderley Brittes e Iracema Hilário Dulley. 
preocupações teóricas contemporâneas, os capítulos de SLS e ST embaralham, no bom sentido do termo, os métodos, os conceitos e as teorias mobilizados para situar, teórica e empiricamente, entidades espirituais no âmbito da prática antropológica.

Cobrindo um amplo espectro etnográfico - do Chaco argentino à Mongólia, de Cuba à Amazônia, do Caribe à Zâmbia, dos Estados Unidos ao Nordeste brasileiro -, ambas as coletâneas tratam, às vezes por meio de pesquisa documental, de xamanismo, de encantados, de neopentecostalismo e de religiões afro-americanas. Contrariando o que se pode imaginar, os livros, salutarmente, não confinam a análise à delimitação de identidades e filiações religiosas, tampouco à descrição de cosmologias e sistemas de crenças. Essa postura metodológica e teórica é bem evidenciada em capítulos como o de Vânia Cardoso (SLS), no qual a macumba no Rio de Janeiro é tratada como uma socialidade inextricavelmente marcada pela presença de espíritos que atravessam fronteiras entre o ritual e o cotidiano, o sagrado e o mundano, o passado e o presente, o privado e o público, o real e o imaginário. A macumba é pensada, então, como um modo de percepção, de imaginação e de engendramento de um cotidiano imbuído da presença de espíritos, e não em termos de uma identidade religiosa (SLS: 94-95).

Com efeito, o vocabulário conceitual da antropologia é posto à prova insistentemente nos dois livros. Tanto na introdução a ST quanto em sua contribuição à obra (capítulo 1), Paul Johnson esboça uma genealogia histórica e político-econômica da possessão espiritual no Atlântico, traçando temas, encontros, lugares e momentos nos quais essa categoria foi forjada, destacada de contextos particulares, universalizada e amplamente replicada em histórias, etnografias e mesmo nas esferas rituais. Segundo o autor, a categorização da possessão espiritual fez recurso a ideias europeias sobre propriedade, contrato, pessoalidade e sociedade, emergindo na metade do século XVII, contexto no qual surgiram novas ideias sobre o Estado, a política nacional e os indivíduos. Empregando continuamente jogos de palavras com o termo inglês possession, Johnson (ST: 35) nota que a categoria possessão espiritual - a posse (possession), ou ocupação de um corpo por agentes invisíveis - emergiu de uma relação analógica com possessões materiais, de terras e de pessoas por sujeitos civis concebidos enquanto indivíduos racionais capazes de possuir coisas e seres humanos, ao invés de serem possuídos por entes imateriais. Nessa conjuntura político-econômica e material, assentada na exploração colonial e na escravização de pessoas, a possessão figurou, para os europeus, como índice da ausência de um self apropriadamente autocontido por aqueles suscetíveis de terem seus corpos possuídos por espíritos e por outras pessoas humanas (ST: 1-5).

$\mathrm{Na}$ perspectiva de Johnson, tanto as classificações antropológicas acerca da possessão espiritual quanto práticas contemporâneas de religiões afro-atlânticas são tributárias de encontros entre noções europeias e africanas, remetendo 
ao regime escravista, no qual significações atribuídas às relações de posse, sujeição e autonomia entre deuses, coisas, corpos e pessoas se (re)formaram (ST: 5). Embora o argumento seja instigante e bem fundamentado, há problemas na argumentação de Johnson, alguns dos quais tratados por Michel Lambek (ST: 259) no capítulo final do livro. Lambek coloca questões pertinentes: até que ponto a possessão espiritual é moldada pela experiência da escravidão ou concebida em analogia a ela? Em que medida a possessão espiritual deve ser entendida como determinada pela política e por forças econômicas? O foco privilegiado em boa parte das contribuições de ST não é, como atesta Johnson, a "fenomenologia das experiências de possessão" (ST: 7), e sim os "encontros de noções europeias e africanas sobre a possessão espiritual, as formas de relacionamento de religiões afro-atlânticas com esse fenômeno e as classificações antropológicas acerca dessas práticas" (ST: 6). De todo modo, como notou Lambek no posfácio de ST, há filosofias embebidas nos sistemas de possessão espiritual (ST: 260) e a "polifonia complexa" associada ao fenômeno não resulta de um mesmo encontro, na medida em que o fetichismo da mercadoria e a escravidão podem ou não estar presentes nos universos sociais relacionados à possessão (ST: 264). ${ }^{2}$ Destaque-se, aliás, que Johnson reconhece a pertinência da crítica de Lambek, ao notar, na introdução (ST: 19) que o ato de ser possuído tece uma rede de relações recíprocas que "mistura tropos de servidão, parceria, soberania, etc."

Isso não exclui a possibilidade de haver correlações entre a possessão espiritual e possessões materiais, tal como sucede nos casos descritos, em ST, por Brazeal acerca da relação entre o comércio de esmeraldas e a possessão na Bahia, e as articulações, tratadas por Selka para o caso da Igreja Universal do Reino de Deus, entre autonomia (libertação da possessão espiritual, da feitiçaria e da ação de demônios) e acumulação (deter e conquistar a posse de bens materiais). Do mesmo modo, as práticas neopentecostais no Haiti, analisadas por McAlister em ST, são marcadas por tentativas de despossuir forças espirituais ancestrais firmemente estabelecidas na terra por meio de rituais nos quais se revela uma dialética entre possessão e desapossamento (ST: 181). O que esses casos demonstram é que as relações entre religião, economia, mercadorias, posse, propriedade, etc. podem assumir contornos vários quando deslindadas etnograficamente.

O escrutínio da categoria possessão espiritual segue outras vias no capítulo de Karen Richman acerca do vodu haitiano em ST. Conquanto estudos sobre a possessão no Haiti assumam que a prática ritual é uma poderosa expressão comunal dos laços entre espíritos e participantes, o enfoque privilegiado na bibliografia especializada foi, segundo Richman, o das transformações

2 Um exemplo sobre como tratar das relações entre memória, bruxaria, colonialismo, capitalismo e tráfico de escravos pode ser encontrado em Shaw (2002). 
individuais, em detrimento das experiências coletivas com ancestrais. Para Richman, negligenciou-se que a possessão é uma performance corporal de interdependência entre membros vivos de um grupo de descendência, membros mortos desse grupo e seus espíritos, os quais conectam memórias familiares, inclusive de posse da terra (ST: 207). Ademais, a fascinação com a "imagética da possessão" no vodu obscureceu uma apreciação mais detalhada de aspectos fundamentais da "comunicação corporificada" de haitianos com espíritos (ST: 207).

Críticas à ênfase visualista na antropologia como um todo (Fabian 1983; Taussig 1993) e no tratamento analítico dispensado à possessão espiritual (Stoller 1995) não datam de hoje, e ambos os livros avançam nesse tocante. No fascinante capítulo escrito por Stephan Palmié em ST acerca dos usos de tecnologias sonoras para mediar, anunciar e amplificar o poder dos espíritos de impingir a percepção sensorial humana, o autor trata das convergências entre as "ideologias auditivas e fônicas de mediação do divino" no ritual afro-cubano de abakuá e as tecnologias de transmissão acústica através do tempo e espaço que reconfiguraram os mundos auditivos ocidentais desde a segunda metade do século XIX. Palmié chama a atenção para o fato de que rituais como o de abakuá consistem na criação de contextos sociais nos quais o simples volume físico, ou o peso semiótico do som, privilegiam a audição como uma modalidade sensorial proeminente em relação a outros aspectos sensoriais (ST: 58-60). A reprodução da voz de espíritos dos mortos constitui, então, uma transformação sônica do mundo e de instanciação espiritual propagada pelo alcance acústico de presenças espirituais (ST: 73-77).

Entidades espirituais estão intimamente atreladas ao que Kristina Wirtz cunhou, em ST, de "economia representacional da presença espiritual", ou seja, ordens semióticas e ontológicas que informam como as pessoas humanas tomam certas coisas como representações de outras, como signos ganham valor indicial como signos (ST: 99). Esse aspecto é fundamental, pois talvez as reflexões em torno dessas questões sejam as principais contribuições de SLS e ST. Tome-se, inicialmente, os capítulos de Kristina Wirtz em ambas as obras. Em ST, a autora explora as ordens semióticas e ontológicas que informam como as pessoas tomam certas coisas como representações de outras, como signos ganham valorações indiciais enquanto signos das materializações espirituais. O reconhecimento da agência imaterial dos espíritos requer um tipo especial de orientação sensorial que pressupõe o inculcamento de uma "fenomenologia cultural específica" na qual os efeitos materiais de agências espirituais tornam-se experiências sensíveis (ST: 100). Desse modo, as qualidades perceptíveis de coisas podem servir como índices da presença espiritual e de sua agência. Os aspectos tangíveis e sensoriais das instanciações materiais de espíritos são fundamentais na medida em que, para os praticantes de religiões afro-cubanas, o mundo material é entendido como permeável e animado por espíritos (ST: 107). 
Como argumenta em SLS, os espíritos manifestam sua agência por meio de várias ordens de materialização (SLS: 131). No contexto trabalhado pela autora, esses seres são entendidos como presenças fugazes que infundem objetos cotidianos e substâncias tratadas ritualmente, ou que causam sensações e transformações corporais (SLS: 133). Desse modo, as manipulações de materiais e intervenções rituais são condições necessárias para materializações espirituais. Em ST, Wirtz nota que ofertas materiais incluem não apenas itens duráveis (e perecíveis) de objetos, animais e alimentos, mas também oferendas mais efêmeras, mas igualmente materiais, como fumaça, cânticos e músicas. Por meio dessas manipulações do mundo material circulam signos da presença espiritual, cujas propriedades indiciais estimulam e moldam a imaginação da vida social dos espíritos (SLS: 118 -119).

Como bem notaram Espírito Santo e Tassi (2013: 3) na introdução a outra coletânea recente, cujo foco é sobre questões de materialidade e transcendência, particularmente as relações entre objetos religiosos com espíritos e humanos, a separação entre o espiritual e o material, presente em boa parte da história do cristianismo, resultou na quase exclusão de investigações acerca da interação e da transformação recíproca entre esses domínios. Segundo Espírito Santo e Tassi, artefatos religiosos transgridem o estatuto ontológico de meros objetos, participando ativamente da criação de cosmologias (2013: 6), podendo ser vistos como pessoas que ocupam posições múltiplas no âmbito da ação religiosa (2013: 8). ${ }^{3}$ Nessa perspectiva, objetos religiosos, palavras, textos, assim como outros materiais (comida, dinheiro, pedras, pedaços de ferro, etc.) não são concebidos como portadores de símbolos, conceitos e significados, mas antes como elementos capazes de produzir transformações ontológicas de diversas ordens, inclusive no plano espiritual (2013: 10). "Entidades processuais potentes", na terminologia de Coupaye (2013: 1 14), as coisas estão continuamente em movimento no tempo e no espaço, carregam consigo trajetórias biográficas, traçam caminhos, forjam relações, geram efeitos na vida das pessoas, não sendo, portanto, meros mediadores, ou meras projeções, de relações sociais e

3 Proposição diretamente tributária de Alfred Gell - cuja influência, aliás, é reconhecida pelos organizadores de Making Spirits, em especial a ideia de que objetos não são, meramente, representações ou veículos de símbolos (Espírito Santo e Tassi 2013: 12). Os problemas da teoria de Gell são bem conhecidos (cf. Ingold 201 1; Henare, Holbraad e Wastell 2007; Leach 2007), dentre eles a concepção de que artefatos são agentes secundários, as distinções entre agentes secundários e primários, agentes e pacientes, recipientes e fontes de causação, etc., bem como os esquematismos implícitos nas reflexões acerca das inesgotáveis combinações de relações entre índices, autores, protótipos e recipientes (Gell 1998: 20-22, 28-50). Deve-se lembrar, contudo, que a análise do material etnográfico apresentado em Art and Agency - vide os casos relativos à possessão e o culto a imagens no hinduísmo, por exemplo - rui as fórmulas propostas pelo próprio autor, aproximando-o de uma definição de agência essencialmente relacional e abrindo caminho para se investigar os efeitos relacionais precipitados pela copresença de coisas e pessoas em um mesmo campo de atores efetuais (cf. Strathern 1999: 17). 
de cosmologias, pois produzem efeitos por meio de seu movimento, de sua circulação, de suas propriedades estéticas e de sua incorporação ao mundo social (Espírito Santo e Tassi 2013: 17).

No capítulo constante em SLS, Wirtz faz a importante advertência de que entidades espirituais podem infundir-se em objetos, corpos, lugares, eventos, falas e sonhos sem que suas presenças, necessariamente, corporifiquem-se ou tomem uma forma material. Com efeito, não é nada supérfluo perguntar se objetos, artefatos e ícones podem ser, simultaneamente, materiais e imateriais (cf. Espírito Santo e Tassi 2013: 13). Em contextos nos quais a iconografia de entidades espirituais é restrita, como ocorre no caso de encantados no Tambor de Mina do Maranhão, descrito por Cunha em SLS, a materialização de entidades se dá em canções, linguagens verbalizadas e sonhos. Ao mesmo tempo, o universo onírico, no qual existem redes sociais preexistentes, parece ser mais do que um espaço de experiência no qual encantados se materializam: poder-se-ia dizer, na esteira de Tim Ingold (2011), que tais seres habitam esse e outros espaços, precipitando efeitos no transitar de pajés entre o "mundo de cá" e o "mundo de lá".

Questões relativas à materialidade conduzem à reorientação do conceito de agência, que deve ser tratado para além daquilo que é empiricamente verificável. Na estimulante introdução a SLS, Diana Espírito Santo e Ruy Blanes caracterizam os capítulos da obra como "diferentes conceitualizações de uma agência dos intangíveis, tentando deslindar a contingência de várias entidades em seus efeitos" (SLS: 1). Daí, segue-se uma reflexão filosófica e epistemológica: reconhecer a relevância antropológica dos mecanismos e efeitos dos domínios assim chamados de invisíveis ou intangíveis, sejam eles constituídos por espíritos, leis, valores monetários ou estruturas quânticas (SLS: 1).

Três grandes problemas são enfrentados, articuladamente, na introdução de SLS: definir e traçar as entidades espirituais e seus efeitos na vida das pessoas; analisar a maneira pela qual esses efeitos se interceptam com o mundo social; e delinear uma antropologia dos intangíveis (SLS: 3-4). Em termos metodológicos, apresentam-se instrumentais para traçar e definir entidades e seus efeitos em locais específicos, em contextos particulares de experiência, atentando para sua materialização em ordens discursivas (SLS: 4). Invocando filósofos pragmatistas (particularmente William James), Espírito Santo e Blanes se perguntam:

"Quais entidades, espíritos e seres tornam-se verdadeiros e evidentes em tal ou qual comunidade? Como isso acontece, e com qual efeito ou valor? Com isso, deve-se perguntar não apenas como conceitos dão à luz a mundos, mas também como entidades podem vir a ser [...] Os capítulos deste livro exploram, etnográfica e teoricamente, entidades espirituais de vários 
tipos, não apenas, ou primariamente, como conceitos ou componentes de cosmologias dadas e compartilhadas, mas como efeitos-no-mundo, com o potencial constante de imprevisibilidade e transgressão (SLS: 6, tradução livre).

O entendimento da noção de efeito, uma noção ampla e um tanto vaga, como admitem os autores, é passível de elaboração etnográfica, conquanto possa-se identificar uma série de preocupações mais gerais no tocante aos efeitos de entidades espirituais, dentre as quais: a centralidade da experiência corporal; a importância da materialidade e de objetos na mediação do conhecimento sobre entidades; diferentes regimes de evidência e validação na determinação do que está agindo; a relevância de biografias individuais e de narrativas no entendimento dos fluxos e fronteiras de agentes invisíveis; a performance e o potencial criativo da linguagem na evocação de intersecção de vidas; o papel da incerteza e da ambiguidade na geração de presenças espirituais (SLS: 17). Assim, cabe investigar sob quais circunstâncias entidades se manifestam, são interpretadas e tornam-se objetos e sujeitos no mundo, que tipos de eventos ou experiências são tomados como índices válidos ou uma causa primária da agência espiritual e que modos de raciocínio, ou sistemas de inferência, são necessários para que entidades venham a existir (SLS: 17).

A tentativa de compreender a agência dos intangíveis a partir da "pragmática de seus efeitos" (SLS: 17) também conduz a indagações acerca do valor analítico e conceitual conferido a entidades não humanas nas etnografias. Espírito Santo e Blanes interessam-se nas “extensões", "rastros", "evidências" e "traços" das formas espirituais de existência, afastando-se de posturas sociologizantes, sem concebê-las como meros epifenômenos de configurações sociopolíticas, históricas ou de fenômenos "mais reais" (SLS: 28). Tal como no caso descrito por Harris em SLS, as histórias sociais de entidades como os encantados revelam muito sobre a história de vida de ribeirinhos na Amazônia e não apenas de formações sociais mais amplas. Dito de outra forma, a partir das reflexões de Giumbelli (SLS), é preciso estar atento para não reduzir os caminhos percorridos por entidades espirituais às formações nacionais, políticas e religiosas nas quais certas práticas (e existências) estão imersas.

Discussões sobre as relações entre espíritos e história abundam em ambos os trabalhos. De fato, essa não é uma temática nova. Debates instigantes sobre a possessão espiritual enquanto meio de transmissão e registro da história questionaram a rentabilidade de se tratar rituais apenas sob o viés sincrônico, ritual e/ou cosmológico. Se aquilo que poderíamos denominar de "irrupções memoráveis" dos espíritos (cf. Lambek 1996: 242) possibilitam pensar “práticas historiográficas indígenas" (Stoller 1995: 32), ou "imagens do passado dos subordinados" (Williams 1990: 133), por meio da possessão espiritual, parece necessário não só estar ciente das consequências de se utilizar alegorias 
históricas para tratar de espíritos (Kwon 2008) ${ }^{4}$ como questionar que tipos de histórias, eventos e narrativas emergem, se reconfiguram e se atualizam com a presença de entidades espirituais nos planos mundano e espiritual.

Como nota Palmié em SLS, deve-se reconhecer que a maneira pela qual se traz uma dimensão histórica à análise antropológica permanece em dívida, metodológica e epistemologicamente, a um conjunto de pressupostos originados no Atlântico Norte. Servindo-se de uma vinheta etnográfica - a interação, em um ritual afro-cubano recente no âmbito de Regla de Ocha, entre espíritos de um sacerdote e de um escravo africano -, Palmié submete, em um exercício de simetrização, as formas ocidentais de historicismo à análise antropológica. A torção analítica de Palmié é deveras notável: o autor não opta por racionalizar a maneira pela qual o passado é presentificado quando os espíritos de mortos interagem com os vivos em cerimônias de possessão ritual afro-cubanas; ao invés disso, o foco volta-se para os modos pelos quais a historiografia historiciza o passado. Embora seja viável descrever qual conhecimento é produzido com base em certas suposições presentes nas formas contemporâneas afro-cubanas, a indagação de Palmié (SLS: 219-220) é a seguinte: pode-se chegar a descrições similares no caso da historiografia ocidental? Em seu capítulo, Palmié escrutina conceitos historicistas de tempo e os comprometimentos metafísicos e ontológicos que as concepções aí embutidas implicam. A hibridização temporal efetuada pela copresença de agentes situados em posições cronológicas distintas (o sacerdote e o escravo) é concebida como uma forma específica de conhecimento semiótico que coloca à prova as garantias epistemológicas dos regimes evidenciários historicistas, que conceberiam, na melhor das hipóteses, a aparição de espíritos como uma forma icônica, simbólica, mas não indicial de um passado concreto (SLS: 220-222, 226).

Os problemas do historicismo não se limitam ao fato de que o processo de construção de arquivos silenciou (cf. Trouillot 1995) as histórias do sacerdote e do escravo africano mortos que interagiram na vinheta etnográfica apresentada por Palmié. Indivíduos cujas vidas foram excessivamente documentadas (como Einstein, Napoleão, George Washington, etc.) não apenas permanecem se comunicando com os vivos em círculos espirituais cubanos, como continuam a produzir escritos após o fim de sua existência terrena por meio de médiuns. As informações adquiridas nessas mensagens - como a mudança de opinião de George Washington, em sua vida pós-morte, sobre a escravidão -

4 Em estudo sobre os espíritos surgidos no Vietnã após a guerra contra os Estados Unidos, Kwon sugere que esses seres não são meros mecanismos históricos alegóricos invocados para direcionar o significado de novos eventos históricos similares aos anteriores. A existência de fantasmas da guerra no Vietnã é percebida como um fenômeno "natural" ao invés de um símbolo cultural, uma questão de ser ou tornar-se no mundo (uma questão ontológica), ao invés de mera alegoria. Na medida em que muitos desses espíritos passam a ser cultuados como ancestrais, eles relacionam-se à história da socialidade da experiência vivida durante e após guerra (Kwon 2008: 15-16, 168). 
conduziriam os historiadores a alargar seu corpus de evidências para tratar da vida desses indivíduos, pergunta-se provocativamente Palmié (SLS: 238-239)?

De fato, como aponta Wirtz em SLS, as biografias de espíritos violam noções empíricas de historicidade (SLS: 136). Como demonstrou Michel Lambek no início da década de 1980, a possessão espiritual instaura canais de comunicação que transmitem mensagens verbais e materiais que podem ser usadas, pragmaticamente, para endereçar certos problemas, dos quais os espíritos tomam parte, dos humanos (Lambek 1981: 28, 70-75, 86). Com efeito, nos momentos nos quais espíritos de distintas épocas interagem simultaneamente, pessoas, pontos de vista e eventos previamente separados no tempo são justapostos e conjugados no espaço. E justamente porque há uma série de validações empíricas de proposições concernentes à natureza dos espíritos nesse processo e reelaborações retrospectivas de situações passadas, as irrupções memoráveis de espíritos instauram canais de comunicação que tornam o passado imperfeito, no sentido gramatical e ontológico (cf. Lambek 1996). Nesse sentido, as próprias reflexões desse autor indicam que há mais coisas em jogo do que uma dimensão textual na possessão espiritual, aspecto privilegiado em sua clássica monografia. ${ }^{5}$

Textos constantes tanto em SLS quanto em ST exploram regimes de evidencialidade e ordens semióticas envolvidas com a produção, circulação e reconhecimento de índices da presença espiritual (Palmié, Wirtz, Kirsh, Delaplace, Espírito Santo e Blanes - SLS; Wirtz e Romberg - ST),${ }^{6}$ bem como pensam as trajetórias históricas e biográficas de entidades espirituais à luz de processos narrativos. Em termos metodológicos, como argumenta Cardoso em SLS, é necessário refletir sobre o próprio papel da narração etnográfica na articulação de estórias sobre o povo da rua da macumba enquanto objeto etnográfico. Ao invés de capturar os eventos em uma narrativa linear que produz uma sequência de eventos discretos que progressivamente iluminam um ao outro até atingirem uma explanação fechada, deve-se forjar mecanismos para permitir que a etnografia seja contaminada pela própria poética do objeto (SLS: 104). Afinal, semelhantemente às histórias sobre o povo de rua, a narrativa etnográfica produz certas relações entre lugares, pessoas e espíritos (SLS: 107).

5 Transações rituais e comunicações mútuas estabelecidas entre divindades e humanos no Sul da Índia são pensadas à luz do perspetivismo por Ishii (2012).

6 Não à toa, um autor frequentemente citado por vários contribuidores das coletâneas é Webb Keane, particularmente por seu questionamento ao privilégio conferido a ideias ou crenças para se definir a religião. Como alternativa, Keane (2008) sugere repensar a relação entre materialidade e a atividade religiosa, bem como as ideias normalmente assumidas como definidoras da religião. Cite-se o argumento segundo o qual o reconhecimento de instâncias de algo conhecível (fenômenos associados à possessão espiritual, por exemplo) deve tomar uma forma semiótica, de modo que o que circula entre as pessoas não são experiências ou ideias; tais instâncias devem ter alguma manifestação material que as faça disponível, interpretável e, na maioria dos casos, replicáveis por outras pessoas: ações corporais, discursos, o tratamento de objetos, e assim por diante (Keane 2008: S1 14). 
Um aspecto importante das estórias sobre o "povo da rua" diz respeito ao "senso do inesperado" (SLS: 93) e ao "ocultamento" dos detalhes de suas vidas, que são reveladas por meio de uma contínua produção de incertezas sobre suas identidades (SLS: 101) - semelhantemente, a dúvida é um elemento central nos encontros de pessoas com fantasmas na Mongólia, cujos espectros não guardam, segundo Delaplace (SLS), uma relação de identidade (e de origem) com uma alma específica a partir do qual foram originados (SLS: 53). Assim, as narrativas sobre entidades espirituais podem figurar como diagramas de relações semióticas que criam histórias e trajetórias de vida para pessoas e entidades não materiais (Wirtz em SLS).

Levar a sério a realidade êmica da possessão espiritual implica em aceitar, também, as dúvidas, suspeições e acusações acerca da veracidade, simulação e autenticidade acerca dos eventos de possessão, assinala com precisão Romberg em ST (Brazeal também trata, em ST, desses pontos). Elemento fundamental das "tecnologias da presença nos rituais de possessão espiritual" (ST: 230), a dúvida articula-se à corporalidade mimética e a discursos de indeterminação, conquanto mudanças dramáticas das estruturas interpretativas e emocionais dos participantes de rituais face à presença de entidades espirituais apontem para a autoridade, intencionalidade e para as consequências implícitas das mensagens transmitidas por espíritos (ST: 243-244). Se a mimese é pensada por Romberg sob a chave da invocação, canalização e transgressão dos poderes de outros, inclusive de memórias incorporadas sobre o passado colonial, Polk, em um dos capítulos de ST, trata da encenação da negritude por menestréis e atores nos Estados Unidos do século XX, a qual é performada por meio da descrição de uma complexa ação recíproca de simbolismo coletivo, fantasia individual e produção da negritude, de modo que a mediunidade permaneceu alinhada com modos textuais, gráficos e teatrais de representação racial (ST: 202).

\section{ETNOGRAFANDO ENTIDADES ESPIRITUAIS}

O principal mérito de SLF e ST repousa, a meu ver, na feliz combinação de pensar entidades espirituais para além dos quadros de referência de domínios especializados da disciplina com a formulação de alternativas metodológicas e teóricas para se etnografar formas extra-humanas de existência. De fato, ambas as obras não se restringem a temáticas específicas, aventurando-se por debates centrais na teoria antropológica contemporânea, colocando em xeque a rentabilidade de métodos, teorias e epistemologias da disciplina como um todo. Os leitores e as leitoras não encontrarão muito espaço para certas temáticas, como a da morte e a do gênero, ${ }^{7}$ tampouco para diálogos com vertentes da

7 Interessante notar que em sua ampla revisão bibliográfica sobre a possessão espiritual, escrita há duas décadas, Boddy (1994: 415-422) dedicou uma seção inteira de seu artigo às relações [continua] 
psicologia. Por outro lado, há alternativas e sugestões estimulantes, algumas das quais destacadas abaixo, em especial aquelas esboçadas pelos organizadores das obras.

Destaco, inicialmente, que o escrutínio de conceitos e categorias mobilizados pela disciplina e, especialmente, pela antropologia da religião, é relevante, bem fundamentado e pertinente. Empreendimentos como os de Paul Johnson chamam a atenção para os riscos de se tomar a possessão como um conceito normalizador (cf. Asad 1993), além de destacar que os eventos de possessão são interseccionados por significações materiais, religiosas, econômicas e políticas, bem como por encontros entre noções europeias e não europeias acerca desse fenômeno. Daí a importância de se precisar, no tempo e no espaço, os encontros, lugares e momentos nos quais a possessão espiritual emerge (ou emergiu) enquanto evento multifacetado. $\mathrm{O}$ viés histórico das proposições de Johnson configura-se como antídoto às análises que pressupõem a existência de sistemas (simbólicos, rituais e cosmológicos) cerrados e autocontidos.

A genealogia da possessão espiritual é um convite salutar para se acertar contas com o fato de que a categoria infiltrou a produção antropológica e as próprias práticas religiosas de maneiras paradoxais. Contudo, não se pode perder de vista que há diversas ordens de hibridização temporal em jogo, seja no plano da longa duração, seja no do presente etnográfico. Ou seja, as relações de entidades espirituais entre elas mesmas e com humanos não só podem reconfigurar situações passadas e presentes, como possibilitam a certos agentes (humanos e não humanos) transitar entre distintas posições cronológicas e ordens temporais. De fato, os eventos em torno da possessão espiritual podem reverberar domínios sobrepostos da religião, economias coloniais expansivas, ideias emergentes sobre a política nacional e a criação do cidadão individual. Mas afinal cabe perguntar: em que medida a realidade da presença de pessoas mortas, espíritos e ancestrais, por exemplo, perturba, nos termos de Palmié, os próprios cânones de análises historicamente orientadas? Lambek (ver acima) parece-me correto ao sustentar que devemos conferir papel central às filosofias embebidas nos sistemas de possessão espiritual, deixando as retóricas da filosofia e antropologia europeias em suspenso em prol da análise das práticas, conhecimentos e discursos locais em seus próprios termos - independentemente de reverberarem ou não as hibridizações aludidas por Johnson. Dito isso, é notável o esforço de autores como Palmié, Wirtz, Cardoso, Giumbelli e Johnson para pensar questões relativas à história sem recorrerem, simplesmente, a um viés historicizante.

Essas considerações conduzem a um ponto central: como entidades espirituais se interceptam com imaginários de resistência e reflexões sobre histórias 
e economias políticas? De meu ponto de vista, Espírito Santo e Blanes avançam significativamente ao questionarem o privilégio normalmente conferido a fenômenos "mais reais" (economia, política, história, etc.) na abordagem de seres intangíveis. Debruçar-se sobre as trajetórias sociais traçadas por essas entidades no mundo - os efeitos da presença de agências extramateriais - tem por contraparte não reduzir tais entidades a epifenômenos da operação analítica de contextualização histórica e sociopolítica.

A influência de estudos associados à chamada virada ontológica é evidente na introdução de SLF, algo recorrentemente destacado por Espírito Santo e Blanes, aliás. E, não à toa, percebe-se um afastamento de explicações sociocêntricas. Contudo, se as ressalvas são extremamente pertinentes, as alternativas propugnadas por ambos pendem mais para a divisão do trabalho do que para a conciliação de abordagens. Afinal, discursos, narrativas e práticas mediadas pelas presenças e efeitos desencadeados por entidades espirituais podem ser repletos de significados históricos críticos e ganham atualidade justamente porque remetem a pressões morais, políticas e sociais contemporâneas (cf. Kwon 2008: 18). A irrupção de lembranças e memórias incorporadas em práticas sociais, processos rituais, hábitos e experiências corporificadas (cf. Shaw 2002: 7) mostra-se central para nossos interlocutores(as) em diversos casos. Assim como a "economia política", a "história" e "forças sociais" não devem ser concebidas, a priori, como as fontes de causação das várias ordens de presença de entidades espirituais no mundo, não se deve afastar, de antemão, a possibilidade de os modos de existência das pessoas remeterem, a seu modo, a dinâmicas e processos relativos a eventos "históricos", por exemplo.

Por fim, ambas as obras deslocam a ênfase excessiva da materialização de entidades espirituais em corpos (algo recorrentemente destacado nos estudos sobre a possessão espiritual) e analisam como esses seres infundem-se em objetos, instrumentos, rituais, discursos, paisagens, rumores, narrativas, etc. Não se trata, cumpre destacar, de ignorar a centralidade da experiência corporal, mas antes de se elucidar as técnicas particulares de discernimento e as capacidades perceptivas envolvidas com o reconhecimento de entidades espirituais como sujeitos e objetos no mundo - a economia representacional e as tecnologias de instanciação da presença espiritual, nos termos de Wirtz e Palmié. Assim, pode-se melhor entender e integrar a alteridade perceptiva e sensorial na prática antropológica, explorando-se os processos por meio dos quais formas de existência outras assumem forma e eficácia em distintos contextos, práticas, rituais e discursos (Espírito Santo e Blanes em SLS). As tentativas de se etnografar seres intangíveis, os quais não estão confinados a corpos, espaços e períodos nitidamente delimitados, colocam em suspenso, portanto, dicotomias arraigadas na disciplina, como materialidade e imaterialidade, tangível e intangível, visível e invisível, real e imaginado, material e mental. 
À guisa de conclusão, ressalto que a riqueza de ST e SLF permitiria outras apropriações e comentários. Seja como for, e não obstante as distintas orientações teóricas presentes nos livros, ambas as obras sinalizam que os procedimentos de confinamento conceitual o/ou disciplinar são postos à prova pela existência e pelas ações de entidades espirituais que se replicam continuamente nos espaços de experiências compartilhadas com os humanos.

\section{BIBLIOGRAFIA}

ASAD, Talal, 1993, Genealogies of Religion: Discipline and Reasons of Power in Christianity and Islam. Baltimore, Johns Hopkins University Press.

BLANES, Ruy, e Diana ESPÍRITO SANTO (orgs.), 2014, The Social Life of Spirits. Chicago, The University of Chicago Press.

BODDY, Janice, 1989, Wombs and Aliens: Spirits, Women, Men, and the Zar Cult in Northern

Sudan. Madison, WI, The University of Wisconsin Press.

BODDY, Janice, 1994, "Spirit possession revisited: beyond instrumentalism", Annual Review

of Anthropology, 23: 407-434.

COUPAYE, Ludovic, 2013, "Knowing what has been done: the techniques of ritual 'objects' among the Abelan (East Sepik Province, Papua New Guinea)", em D. Espírito Santo e

N. Tassi (orgs.), Making Spirits: Materiality and Transcendence in Contemporary Religions. Londres, I. B. Tauris, 105-132.

ESPÍRITO SANTO, Diana, e Nico TASSI, 2013, "Introduction”, em D. Espírito Santo e

N. Tassi (orgs.), Making Spirits: Materiality and Transcendence in Contemporary Religions. Londres, I. B. Tauris, 1-32.

FABIAN, Johannes, 1983, Time and the Other: How Anthropology Makes Its Object. Nova Iorque, Columbia University Press.

GELL, Alfred, 1998, Art and Agency. Oxford, Clarendon Press.

HENARE, Amiria, Martin HOLBRAAD, e Sari WASTELl, 2007, "Introduction: thinking through things", em A. Henare, M. Holbraad e S. Wastell (orgs.), Thinking through Things: Theorising Artefacts Ethnographically. Londres, Routledge, 1-31.

INGOLD, Tim, 2011 , “The textility of making”, em T. Ingold, Being Alive: Essays on Movement, Knowledge and Description. Londres, Routledge, 210-219.

ISHII, Miho, 2012, "Playing with perspectives: spirit possession, mimesis, and permeability in the buuta ritual in South India", JRAI: Journal of the Royal Anthropological Institute, n. s., 19 (4): 795-812.

JOHnSON, Paul (org.), 2014, Spirited Things: The Work of Possession in Black Atlantic Religions. Chicago, The University of Chicago Press.

KEANE, Webb, 2008, "The evidence of senses and the materiality of religion”, JRAI: Journal of the Royal Anthropological Institute, n. s., 14: S110-S127.

KWON, Heonik, 2008, Ghosts of War in Vietnam. Cambridge, Cambridge University Press. 
LAMBEK, Michael, 1981, Human Spirits: A Cultural Account of Trance in Mayotte. Cambridge, Cambridge University Press.

LAMBEK, Michael, 1996, “The past imperfect: remembering as moral practice”, em P. Antze e M. Lambek (orgs.), Tense Past: Cultural Essays in Trauma and Memory. Nova Iorque, Routledge, 235-255.

LEACH, James, 2007, "Differentiation and encompassment: a critique of Alfred Gell's theory of the abduction of creativity", em A. Henare, M. Holbraad e S. Wastell (orgs.), Thinking through Things: Theorising Artefacts Ethnographically. Londres, Routledge, 167-188.

LEWIS, Ion, 1971, Ecstatic Religion: A Study of Shamanism and Spirit Possession. Londres, Penguin Books.

MALINOWSKI, Bronislaw, 1988 [1916], "Baloma: os espíritos dos mortos nas ilhas Trobriand”, em B. Malinowski, Magia, Ciência e Religião. Lisboa, Edições 70.

SHAW, Rosalind, 2002, Memories of the Slave Trade: Ritual and the Historical Imagination in Sierra Leone. Chicago, The University of Chicago Press.

STOller, Paul, 1995, Embodying Colonial Memories: Spirit Possession, Power and the Hauka in the West Africa. Londres, Routledge.

STRATHERN, Marilyn, 1999, “The ethnographic effect I”, em M. Strathern, Property, Substance and Effect: Anthropological Essays on Persons and Things. Londres, The Athlone Press, $1-26$.

TAUSSIG, Michael, 1993, Mimesis and Alterity: A Particular History of the Senses. Londres, Routledge.

Trouillot, Michel-Rolph, 1995, Silencing the Past: Power and the Production of History. Boston, Beacon Press.

TYLOR, Edward B., 1871 , Primitive Culture. Londres, John Murray.

WILLIAMS, Brackette, 1990, "Dutchman ghosts and the history mystery: ritual, colonizer, and colonized interpretations of the 1763 Berbice slave rebellion", Journal of Historical Sociology, 3 (2): 133-165. 